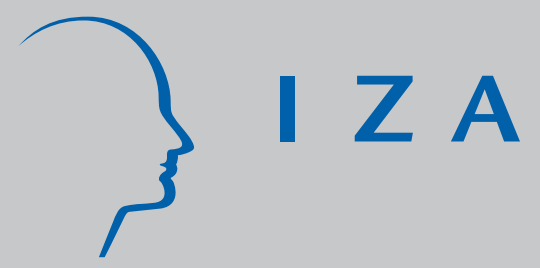

IZA DP No. 1047

Transition Patterns for the Welfare Reliance of Low Income Mothers in Australia

Xiaodong Gong

March 2004 


\title{
Transition Patterns for the Welfare Reliance of Low Income Mothers in Australia
}

\author{
Xiaodong Gong \\ RSSS, Australian National University \\ and IZA Bonn \\ Discussion Paper No. 1047 \\ March 2004
}

\author{
IZA \\ P.O. Box 7240 \\ 53072 Bonn \\ Germany \\ Phone: +49-228-3894-0 \\ Fax: +49-228-3894-180 \\ Email: iza@iza.org
}

\begin{abstract}
Any opinions expressed here are those of the author(s) and not those of the institute. Research disseminated by IZA may include views on policy, but the institute itself takes no institutional policy positions.

The Institute for the Study of Labor (IZA) in Bonn is a local and virtual international research center and a place of communication between science, politics and business. IZA is an independent nonprofit company supported by Deutsche Post World Net. The center is associated with the University of Bonn and offers a stimulating research environment through its research networks, research support, and visitors and doctoral programs. IZA engages in (i) original and internationally competitive research in all fields of labor economics, (ii) development of policy concepts, and (iii) dissemination of research results and concepts to the interested public.
\end{abstract}

IZA Discussion Papers often represent preliminary work and are circulated to encourage discussion. Citation of such a paper should account for its provisional character. A revised version may be available on the IZA website (www.iza.org) or directly from the author. 


\section{ABSTRACT \\ Transition Patterns for the Welfare Reliance of Low Income Mothers in Australia*}

This paper analyzes the mobility of low income mothers in Australia between two groups of governmental transfer payments: Income support payments (IS) and Family Payments (FP, non-income support payments) only. While IS payments are to provide a subsistence of living for her, FP payments are to help low-medium income families with the costs of dependent children. We use a dynamic multinomial logit panel data model with random effects, explaining the reliance of each individual on the income support system during each quarter between 1997 and 2000. The data is drawn from the FaCS 1\% Longitudinal Data Set (LDS), a sample of fortnightly administrative records of welfare payments in Australia. We find that both state dependence and unobserved heterogeneity play significant roles. We also find that single mothers and females with partners on income support payments are much more likely to be on income support than otherwise.

JEL Classification: $\quad$ C23, C25, I38, P36

Keywords: mobility, panel data, welfare reliance, females

Corresponding author:

Xiaodong Gong

RSSS

Australian National University

Canberra ACT 0200

Australia

Tel.: +6126125 4235

Email: gong@coombs.anu.edu.au

\footnotetext{
* The author thanks ARC and the Department of Family and Community Services (FaCS) for providing the grant for this research. The views expressed in this paper are those of the author and do not necessarily represent those of FaCS. The author also thanks Bob Gregory, Prem Thapa, Vic Pearse, and the seminar participants at University of New South Wales and RSSS, ANU for their useful comments and suggestions.
} 


\section{Introduction}

This paper studies the general pattern and the dynamics of welfare dependency of low income females with dependent children using a dynamic multinomial logit panel data model with random effects, using 1\% Longitudinal Data Set (LDS) from Department of Family and Community Services.

Three 'states' are defined for each individual: on income support programs (see below); on Family Payments (more than the minimum rate, see below) only; and 'out' - a state which indicates that the individual is not in the income support system.

The concept of income support in Australia is often used in two senses: a broad one and a narrow one. In the broad sense, the social security system administered by the Commonwealth Government is often called income support system. The system is rather complicated, but can be classified into two layers: the first layer consists of more than twenty payments (pensions and benefits) which are designed to provide a subsistence standard of living for an adult, i.e., the main source of income for those individuals. For example, the most important payments for an individual with children are Parenting Payment Single (for single parents, PPS thereafter) or Parenting Payment Partnered (for partnered parents, PPP thereafter). These payments are taxable income and one individual can only get one of them at a time. These payments are often called income support programs. Hence, the narrow sense of income support means these programs.

In addition to the income support payments, the second layer of the system is an extensive system of not-mutually-exclusive supplementary payments, which are called non-income-support payments. For families with children, these are basically Family Payments $^{1}$. These supplementary payments are meant to assist rather than to provide the main source of income for those families. They are designed to help the low income families in raising their children and to ensure these families are not worse off financially than those entirely on income support. They are not taxable, however, they are also income-tested. The most important non-income support payment for family with dependent children is Family Allowance (FA), which is paid to the carer of children (usually the mother). Depending upon the families income, the family can get maximum rate of FA, more than minimum rate of FA, minimum rate of FA, and none. For more details on Australian income support system, see Whiteford (2000).

To make things clear, we will use the term 'income support system' to refer to the whole social security system (the broad sense) and the term 'income support' to refer to those pensions and benefits in this system (the narrow sense, and IS thereafter).

It is the transitions of females with dependent children between these two layers of the income support system that is the focus of this paper. Due to the data limitation, we only observe individuals who receive an IS payment or do not receive an IS payment but receives more than the minimum rate of $\mathrm{FA}$. So the population studied is reduced to the females with dependent children who receives an IS payment or more than minimum

\footnotetext{
${ }^{1}$ Since the tax reform in the year 2000, Family Payments are replaced by Family Tax Benefits.
} 
rate of FA only (mothers hereafter). Relatively speaking, these are the low income mothers. ${ }^{2}$ The ones who receive the minimum rate of FA are not considered.

To illustrate the distinction of the states defined in this paper, Figure 1 describes a single mother with one child aged under 13 years in 2000 (just before the tax reform). When her income is low enough $(<\$ 22900$ per year), the mother is qualified for an income support payment, for example PPS, then she is in the first state, IS. As the carer, she also automatically gets the maximum rate of FA.

Beyond that income level $(\$ 22900)$, she only gets FA (the maximum rate). When her income reaches certain level (\$24350 per year), FA is reduced at a rate of 50 cents per extra dollar of family income, until the income level reaches $\$ 28300$ per year. So for her income between $\$ 22900$ and $\$ 28300$, she is in the second state, receiving the more than minimum rate of FA only. If her income increases further, until it is below a fairly high income level ( $\$ 68600$ per year), she will only get the minimum rate of FA.

The distinction of the states between receiving IS payments or FA only is important. If a mother receives an income support payment (and automatically receives FA), the payment forms at least part of the main income for her living. Many IS payments recipients do not have private income at all. On the other hand, if an individual only receives FA, she has other sources of private income and the government income support system only plays a limited role in assisting her to meet the additional costs of raising children. So to speak, she does not rely on the government for her primary income.

The aim of this paper is to describe the mobility patterns of the individuals between these states over time. In particular, we try to identify and distinguish the impacts of observed and unobserved individual characteristics and that of welfare reliance history on welfare dependency: are some women given certain characteristics are more likely to rely on welfare than others (heterogeneity), or once individuals are on certain welfare program, are they more likely to stay there (state dependence)? The distinction has rather important policy implication. For example, if state dependence is important, the so called 'welfare trap' exists, then the preferred policy would be to prevent individuals from 'dropping' into welfare for the first place. On the other hand, if individuals with certain characteristics are more likely to be on welfare than others, it would be harder for most of policies to take effect in the short run. By answering this question, we also hope to shed some light on the reason why the welfare dependency of this group of people has increased.

To date, research has focussed on certain specific types of payments and on certain groups of individuals. For example, Barrett (2000), using the 1\% LDS data, studies the duration of individuals receiving single parents pensions, where by estimating a duration model, he concludes that the average time spent on one episode of the payment was about two years and heterogeneity plays an important role on the length for the individual staying on the payment. The emphasis on the length of a single type of payment is very

\footnotetext{
${ }^{2}$ It depends upon the number of dependent children. The more children she has, the higher the family income could be to get more than the minimum rate of FA.
} 
limited as a measurement of welfare dependency. A recent descriptive study by Gregory and Klug (2003) investigates the duration on all kinds of income support programs of a cohort of lone parents in 1995. They find that most of the people were 'long term income support customers' although the duration on the single payment were relatively short. They also find that there is considerable mobility between different types of payments.

Compared to previous studies, this paper focus on all low income mothers instead of lone parents. This will cover most low income families with children except for a small number of families where children live with their fathers only. ${ }^{3}$ As in Gregory and Klug (2003), we study the welfare dependency in terms of all income support payments instead of just one single type of payment, but more formally. The paper takes a different approach from duration models. By estimating a dynamic multinomial logit panel data model with random effects, we model the transition probability directly, which makes it much more straightforward to analyze the impacts of heterogeneity by simulations. The model is a variation of the first-order Markov models proposed in Heckman (1981a), where 'true' structural state dependence and heterogeneity are distinguished by including dummies for the one period lagged labor market state, as well as unobserved individual random effects. The initial condition problem associated with this kind of model is treated following the procedure proposed by Heckman (1981b).

The remainder of the paper is organized as follows. Section 2 describes the data. The econometric model is discussed in Section 3. The estimation results are discussed in Section 4. Moreover, to interpret the meaning of the parameter estimates, we use the model to simulate transition probabilities for groups with various background characteristics. Conclusions are drawn in section 5 .

\subsection{Data}

The analysis is based upon the FaCS 1\% Longitudinal Data Set (LDS), a sample of fortnightly administrative record for $1 \%$ of all individuals who received income support payments (and certain non-income support payments) during period of January, 1995 to June 2000. It is used widely for analyzing welfare issues in Australia (another example is Kumar and De Maio, 2002). As administrative data, it has the advantage of not being subject to non-response or recall error as in survey data. However, it also has a number of disadvantages. One is that it is not possible to track individuals once they leave the program. Hence it makes it impossible to investigate the transitions into the income support system. Another is, as most of administrative data sets, that it contains only a limited number of socioeconomic variables. For example, it does not include variables which are important in explaining the welfare reliance like education, most of information on family background, employment, education, and so on. Nevertheless, by controlling for the unobserved heterogeneity in the model, the problem is taken into account.

\footnotetext{
${ }^{3}$ About $7 \%$ of Sole parents are males (FaCs, 2000).
} 
The one percent LDS data set includes all of the fortnightly records of one percent individuals who received income support payments or more than the minimum rate of FA, or the partners of individuals who receive income support payments - effectively individuals from low income families. The information available include variables about the payments the individual received such as the type of payments, and basic demographic variables such as the individuals's age, country of birth, whether the individual is identified as Aboriginal or a Torres Strait Islander, the number of dependent children, and the age of the youngest child. There is also information on home-ownership and private income. However, there is no information once the individual leaves the system which could be because of change of employment, marital status, family composition (for example, the presence of dependent children), and so on. The sample available is from January 1995 until June 2000 (22 quarters). All together, there are 45030 females. However, due to some reasons, the data quality for the first two years are not as good as later, so our analysis is based upon the records from 1997 onwards. We only focus on the 14 quarters' data for 14985 females who were younger than 51 when they are first observed, and with children under 16 (hereafter, mothers). Based upon the type of payments the individual received, we create a variable indicating her status on the income support system: she receives income support payments, receives more than the minimum rate of FA only (to ease the wording, we refer it as 'FA only'), and 'out' (of the system or of the motherhood of dependent children). The original records were fortnightly, to reduce the superfluous transitions caused by administrative operations, we aggregate the data into quarterly, i.e., a person is treated as receiving IS payments if she received IS payments more than half of the time in that quarter, otherwise as receiving FA only. The aggregation may also induce measurement errors, too. To check how serious this might be, we compare the variable generated this way and the status at the beginning of each quarter in Table 1 . It shows that for less than $2 \%$ of the cases the two has discrepancy, and for the $98 \%$ of the cases, it makes no difference at all.

Table 1. Aggregated vs snap-shot status (in \%)

\begin{tabular}{r|ccc}
\hline \hline & \multicolumn{3}{|c}{ Aggregated } \\
\hline Snap-Shot & FA only & IS payment & Total \\
\hline FA only & 30.43 & 0.78 & 31.21 \\
IS payment & 1.06 & 67.73 & 68.79 \\
\hline Total & 31.49 & 68.51 & 100.00
\end{tabular}

Snap-shot status is on the first day of each quarter.

The absolute number of mothers on income support system remains rather constant over the period and even dropped a bit by the end. In January 1997, there are 8988 individuals on the system, and by June 2000, 8491 persons (see Figure 2 for the whole trend). It also shows that the number of new customers is also quite stable over time. However, the composition of these people changes over time. Plotted in Figure 3 are the proportions over time of: all low income mothers who received an income support 
payment, who partnered with somebody, and who had private incomes. It shows about $68 \%$ of the mothers received income support payments in January 1997 and increased to about $73 \%$ in the second quarter of 2000 . This implies that on average, welfare dependency of females with young children increased over this period. From Figure 3, one can also see that in January 1997, about 56\% of them were partnered - the rest $44 \%$ were lone mothers. However, from 1998, the proportion of single mothers increased steadily. By June 2000, the end of the sample period, the proportion of single mothers increased to $49 \%$. Figure 3 also shows the proportion of the mothers who had private income. It also dropped at the end of sample period. It seems that the increasing welfare dependency associates at least partly with the change of composition of this group, especially, the increase of single mothers and/or incomeless mothers.

In Table 1 we present the sample statistics at January 1997, for the sample as a whole as well as for single mothers and partnered mothers separately (the explanations of the variables are in Table A1 of the appendix). The table shows that the mothers were fairly young with average age being about 34 year and youngest child being 6 years old. They received very little private income with the average income of 310 dollars per fortnight. Altogether, $55 \%$ of these females lived in the major eight Australian capital cities.

Of those who partnered with a man, about $37 \%$ had partners receiving Income Support payments. ${ }^{4}$

Examining the data more closely reveals that partnered female recipients and lone mothers exhibit rather different characteristics. There are more Aboriginal among single mothers than among partnered ones, on the other hand, more partnered mothers are foreign born than single mothers. On average, single mothers were one year younger than the partnered mothers whose average age was about 34, and they had fewer young children under 13 than the partnered ones, but their youngest child were almost one year older than the partnered ones'. The average age of the youngest children for the two groups were 6.3 and 5.4, respectively. On average, about $33 \%$ of the individuals own their homes. The home ownership was much lower among single mothers $(19 \%)$ than the partnered mothers (43\%). Single mothers also stayed much longer than the partnered on the system. Table 1 also shows that about $54 \%$ of partnered mothers were on income support payments, but $88 \%$ of single mothers were on various income support payments.

Equally important to the issue as composition of individuals with various characteristics is the mobility patterns. In Table 2, the average sample probabilities of the transitions between different states are presented. It shows that the mobility of the mothers who received FA only is higher. For example, on average, given that they received an income support payment, $93.8 \%$ of individuals remained on income support

\footnotetext{
${ }^{4}$ These numbers are the conditional sample probabilities and are calculated from the unconditional ones in Table 1. For example, $37 \%$ is calculated from 0.211 (the proportion of partners on IS) divided by 0.568 (the proportion of partnered).
} 
payments a quarter later, $3.1 \%$ of them received FA only, and only $3.0 \%$ of them left the system. On the other hand, if they received FA only, only $84.4 \%$ of them remained there a quarter later, and $8.9 \%$ left the system. Looking at single and partnered mothers separately, we can see that about $90.8 \%$ of the partnered mothers stayed in income support payments, but about $96.1 \%$ of single mothers stayed there. At the same time, only about $5.6 \%$ partnered mothers who were on FA only fell to IS a quarter later, but about $11.8 \%$ single mothers fell from FA only to IS.

Table 2. Sample Statistics at January 1995

\begin{tabular}{|c|c|c|c|}
\hline Variables & Wholesample & Partnered & Single \\
\hline atsi & 0.036 & 0.023 & 0.053 \\
\hline aussi & 0.779 & 0.738 & 0.833 \\
\hline inc & 310.022 & 405.952 & 184.075 \\
\hline & $(427.14)$ & $(476.67)$ & $(309.46)$ \\
\hline dura & 787.327 & 598.371 & 1035.410 \\
\hline & $(1290.99)$ & $(1248.73)$ & (1303.67) \\
\hline kids 13 & 1.689 & 1.889 & 1.426 \\
\hline & $(1.07)$ & $(1.13)$ & $(0.94)$ \\
\hline$k i d s 13-15$ & 0.324 & 0.343 & 0.300 \\
\hline & $(0.57)$ & $(0.59)$ & $(0.53)$ \\
\hline kids 15 & 0.047 & 0.054 & 0.038 \\
\hline & $(0.22)$ & $(0.24)$ & $(0.20)$ \\
\hline ykidage & 5.764 & 5.350 & 6.308 \\
\hline & $(4.30)$ & $(4.19)$ & $(4.38)$ \\
\hline age & 33.961 & 34.404 & 33.380 \\
\hline & $(7.46)$ & $(7.06)$ & $(7.92)$ \\
\hline dis & 0.684 & 0.538 & 0.876 \\
\hline partnered & 0.568 & 1.000 & 0.000 \\
\hline dhown & 0.327 & 0.433 & 0.189 \\
\hline dpis & 0.211 & 0.372 & 0.000 \\
\hline sydney & 0.177 & 0.167 & 0.190 \\
\hline melbourne & 0.150 & 0.155 & 0.143 \\
\hline brisbane & 0.078 & 0.076 & 0.079 \\
\hline adelaide & 0.059 & 0.059 & 0.058 \\
\hline perth & 0.063 & 0.057 & 0.072 \\
\hline hobart & 0.009 & 0.007 & 0.012 \\
\hline darwin & 0.004 & 0.003 & 0.006 \\
\hline canberra & 0.010 & 0.009 & 0.011 \\
\hline Obs. & 8988 & 5102 & 3886 \\
\hline
\end{tabular}

Standard deviations are in the parentheses. 
Table 3. Average Transition Quarterly (in \%)

\begin{tabular}{|c|c|c|c|c|}
\hline \multirow{2}{*}{ Whole sample } & \multicolumn{4}{|c|}{$\bar{t} t+1$ given $t$} \\
\hline & \multirow[b]{2}{*}{ IS payment } & \multirow[b]{2}{*}{ FA only* } & \multirow[b]{2}{*}{ Out } & \multirow[b]{2}{*}{ Total } \\
\hline$t$ & & & & \\
\hline IS payment & 93.8 & 3.1 & 3.0 & 68.09 \\
\hline FA only & 6.7 & 84.4 & 8.9 & 31.91 \\
\hline Total & 66.0 & 29.1 & 4.9 & 100 \\
\hline Partnered & & & & \\
\hline$t$ & IS payment & FA only & Out & \\
\hline IS payment & 90.8 & 5.2 & 4.0 & 52.17 \\
\hline FA only & 5.6 & 85.4 & 8.9 & 47.83 \\
\hline Total & 50.1 & 43.6 & 6.4 & 100 \\
\hline Single & & & & \\
\hline$t$ & IS payment & FA only & Out & \\
\hline IS payment & 96.1 & 1.6 & 2.3 & 87.83 \\
\hline FA only & 11.8 & 79.5 & 8.7 & 12.17 \\
\hline Total & 85.8 & 11.1 & 3.1 & 100 \\
\hline
\end{tabular}

* More than the minimum rate

The sample included everyone who had or started to have children under 16 during the whole sample period, so it is an unbalanced panel. Table 3 describes the distribution of the observed durations since 1997. About $31 \%$ individuals stayed on for almost the whole sample period and about half $(50.6 \%)$ are observed for less than two years. Again, the partnered mothers were much shorter on the system. It shows for example that only $21 \%$ of partnered mothers were on the system for more than 13 quarters, as oppose to $44 \%$ for single mothers.

Table 4. Distribution of duration on the system(1997-2000)

\begin{tabular}{r|ccc}
\hline \hline No. of quarters & \multicolumn{3}{|c}{ Percent } \\
& Whole sample & Partnered & Singles \\
\hline 1 to 4 & 30.90 & 35.14 & 24.25 \\
5508 & 19.66 & 20.22 & 18.81 \\
9 to 12 & 13.31 & 13.52 & 12.96 \\
13 to 14 & 26.13 & 21.12 & 43.98 \\
\hline
\end{tabular}

\section{$2 \quad$ Model and Estimation Method}

To explain the welfare reliance of each individual in each quarter, we use a dynamic multinomial logit panel data model with random effects. This model is similar to the first-order Markov model proposed in Heckman (1981a). The model distinguishes between 'true' structural state dependence and unobserved heterogeneity by including lagged state dummies as explanatory variables and individual effects to control for the 
unobserved characteristics. The individual effects are assumed to be independent of the observed characteristics (and therefore called random effects) and to follow a multivariate normal distribution. It is a reduced-form model. The initial condition problem associated with applying this model to a short panel is treated as in Heckman (1981b).

More precisely, individual $i(=1, \ldots, n)$ can be in any of 3 possible states at time $t$ : receiving income support payment $(j=1)$, receiving more than the minimum rate of FA only $(j=2)$, and leaving the system $(j=3)$.

The third state can be seen as an absorbing state. Once the individual leaves the system, there is no information for her. It is also not possible to identify the reason for them to leave the system, which could be higher income, partnering with somebody, children turned to 16 or losing the custody of children under 16, and so on. This state is included in the model to control the possible sample selectivity bias. For example, if individuals receiving FA only tend to leave the system more often, not taking this into account will bias the estimates. The "utility" of state $j(j=1, \ldots, J)$ in time period $t>1$ is specified as

$$
V(i, j, t)=X_{i, t-1}^{\prime} \beta_{j}+Z_{i t} \gamma_{j}+\alpha_{i j}+\epsilon_{i j t},
$$

where $X_{i, t-1}$ is a vector of explanatory variables in the previous period, which includes age, regional dummies, family composition, etc.. $Z_{i t}$ is a dummy variable indicating the lagged state: 1 if receiving more than the minimum rate of FA only, 0 otherwise. $\beta_{j}$ and $\gamma_{j}$ are parameters to be estimated. $\alpha_{i j}$ is a random effect reflecting time constant unobserved heterogeneity. Noting that many variables such as education and other individual characteristics are missing, including the random effect seems to be of particular importance. To identify the model, $\beta_{1}, \gamma_{1}$, and $\alpha_{i 1}$ are normalized to 0 . The $\epsilon_{i j t}$ are i.i.d. error terms. They are assumed to be independent of the $X_{i, t-1}$ and $\alpha_{i j}$, and are assumed to follow a Type I extreme value distribution. Hence, the probability for individual $i$ to be in state $j$ at time $t>1$, given characteristics $X_{i t}$, random effects $\alpha_{i j}$ 's and the lagged state dummies, can be written as

$$
P_{t}=P\left(j \mid X_{i, t-1}, Z_{i t}, \alpha_{i 1}, \alpha_{i 2}, \alpha_{i 3}\right)=\frac{\exp \left(X_{i, t-1}^{\prime} \beta_{j}+Z_{i t} \gamma_{j}+\alpha_{i j}\right)}{\sum_{s=1}^{3} \exp \left(X_{i, t-1}^{\prime} \beta_{s}+Z_{i t} \gamma_{s}+\alpha_{i s}\right)},
$$

Let $\boldsymbol{\alpha}_{\boldsymbol{i}} \equiv\left(\alpha_{i 2}, \alpha_{i 3}\right)^{\prime}$. The $\boldsymbol{\alpha}_{\boldsymbol{i}}$ are assumed to follow a multivariate normal distribution. In other words, the $\alpha_{i j}$ are specified as linear combinations of 2 independent $N(0,1)$ variables:

$$
\boldsymbol{\alpha}_{\boldsymbol{i}}=\boldsymbol{A} \boldsymbol{\eta}_{\boldsymbol{i}}, \text { with } \boldsymbol{\eta}_{\boldsymbol{i}} \sim N_{2}\left(0, I_{2}\right)
$$

where $\boldsymbol{A}$ is a $2 \times 2$ lower triangular parameter matrix to be estimated. The covariance matrix of $\boldsymbol{\alpha}_{\boldsymbol{i}}$ is then given by $\Sigma_{\alpha}=\boldsymbol{A} \boldsymbol{A}^{\prime}$.

Due to the presence of the lagged dependent variables in $Z_{i t}$, an initial conditions problem arises. This can be dealt with in several ways, for example, assuming the initial states and the random effects are independent, the dynamic process being in equilibrium, Heckman (1981b)'s reduced form initial condition approach, and conditional (on 
initial conditions) likelihood approach by Wooldridge (2002). None of them seems to be completely satisfactory, however, in practice, the approach proposed by Heckman (1981b) seems to work well: for time $t=1$, a static logit model is used, with $X_{i 1}$ as the explanatory variables and not including $Z_{i t}$. The specification of $V(i, j, 1)$ is as follows:

$$
V(i, j, 1)=X_{i 1}^{\prime} \pi_{j}+\theta_{i j}+\epsilon_{i j 1}
$$

where $\pi_{j}$ is a vector of parameters and $\theta_{i j}$ is the random effect; As before, the errors $\epsilon_{i j 1}$ are assumed to be independent of all $X_{i t}$ and $\alpha_{i j}$ (and $\theta_{i j}$ ), and of all $\epsilon_{i j t}$ in other time periods $t$, and are assumed to be i.i.d. with a Type I extreme value distribution. The probability for individual $i$ to be in state $j(j=1,2)$ at time $t=1$, given $X_{i 1}$ and the random effects $\boldsymbol{\theta}_{\boldsymbol{i}}=\theta_{i 2}, \theta_{i J}$, can thus be written as another simple logit expression,

$$
P_{1} \mid j<3=P_{1}\left(j \mid X_{i 1}, \boldsymbol{\theta}_{\boldsymbol{i}}, j<3\right)=\frac{\exp \left(X_{i 1}^{\prime} \pi_{j}+\theta_{i j}\right)}{\sum_{s=1}^{2} \exp \left(X_{i 1}^{\prime} \pi_{s}+\theta_{i s}\right)}
$$

Again, $\pi_{1}$ and $\theta_{i 1}$ are normalized to 0 . If (4) is interpreted as a reduced form of the dynamic model, the random effects $\theta_{i j}$ can be seen as induced by unobserved heterogeneity in (1), so that they will be functions of $\boldsymbol{\alpha}_{\boldsymbol{i}}$. Since we only observe individuals who were on the system in period 1 , only the distribution of $\theta_{i 2}$ can be identified. We therefore assume that

$$
\theta_{i 2}=c \alpha_{i 2}=b \eta_{i}
$$

where $b$ is the variance of $\theta_{i 2}$ which is to be estimated.

The model can be estimated by Maximum Likelihood. If the random effects $\boldsymbol{\eta}_{\boldsymbol{i}}$ (or $\boldsymbol{\alpha}_{\boldsymbol{i}}$ and $\left.\theta_{i 2}\right)$ were observed, the likelihood contribution of individual $i$ with observed states $j_{1}, \ldots, j_{T}$ would be given by

$$
L_{i}\left(\boldsymbol{\eta}_{\boldsymbol{i}}\right)=P_{1}\left(j_{1} \mid X_{i 1}, \theta_{i 2}, j_{1}<3\right) P\left(j_{2} \mid X_{i 2}, Z_{i 2}, \boldsymbol{\alpha}_{\boldsymbol{i}}\right) \cdots P\left(j_{T} \mid X_{i T}, Z_{i T}, \boldsymbol{\alpha}_{\boldsymbol{i}}\right)
$$

This is straightforward to compute, since it is a sequence of multinomial logit probabilities. Since the individual effects are not observed, however, the likelihood contribution will be given by the expected value of (7):

$$
L_{i}=\int_{-\infty}^{\infty} \int_{-\infty}^{\infty} L_{i}\left(\boldsymbol{\eta}_{\boldsymbol{i}}\right) \varphi\left(\boldsymbol{\eta}_{\boldsymbol{i}}\right) \mathrm{d} \eta_{i 2} \mathrm{~d} \eta_{i 3}
$$

where $\varphi\left(\boldsymbol{\eta}_{\boldsymbol{i}}\right)$ is the joint density function of $\boldsymbol{\eta}_{\boldsymbol{i}}$. Computation of the likelihood contribution in (8) involves 2 dimensional integration. Various numerical techniques exist to approximate the integral. We will use a (Smooth) Simulated Maximum Likelihood approach, which also works for larger values of $J$. It is based upon the fact that (8) is the expected value of (7); the expected value is approximated by a simulated mean. For each individual, $R$ values of $\boldsymbol{\eta}_{\boldsymbol{i}}$ are drawn from $N_{2}\left(0, I_{2}\right)$, and the average of the $R$ likelihood values conditional on the drawn values of $\boldsymbol{\eta}_{\boldsymbol{i}}$ are computed. The integral in (8) is thus replaced by

$$
L_{i}^{R}=\frac{1}{R} \sum_{q=1}^{R} L_{i}\left(\boldsymbol{\eta}_{i}^{q}\right)
$$


The resulting estimator is consistent if $R$ tends to infinity with the number of observations $(n)$. If $n^{1 / 2} / R \rightarrow 0$ and with independent draws across observations, the method is asymptotically equivalent to maximum likelihood, see Lee (1992) or Gourieroux and Monfort (1993), for example. In our empirical setting, we used $R=30$. To check the sensitivity of the results for the choice of $R$, we also estimated the model for $R=20$, and found little change in the results when we increased $R$ from 20 to 30 .

\section{Results}

\section{Estimates}

Presented in Table 5 are the estimates of the dynamic equation in (1). The estimates of the static reduced form equation (4) are reported in Table A2 of the appendix. Due to the nonlinearity of the model, the coefficients are hard to interpret. The effects on the probabilities are not linear to the parameters, and their directions do not necessarily follow the signs of the coefficients as in a binary logit model. To see this, let $p_{1}$ be the probability of receiving income support payments (the reference state) at time $t>1$, given $x_{t}$, random effects, and the lagged status, $p_{2}$ be that of receiving FA only, and $p_{3}$ be that of leaving the sample. Let the coefficients of the variable corresponding to the two non-reference states to be $\beta_{2}$ and $\beta_{3}$. It is straightforward that the effects of a variable $x_{t}$ on these three probabilities are given by

$$
\begin{array}{r}
\partial p_{1} / \partial x_{t}=-p_{1}\left(\beta_{2} p_{2}+\beta_{3} p_{3}\right) \\
\partial p_{2} / \partial x_{t}=p_{2}\left(\beta_{2}\left(1-p_{2}\right)-\beta_{3} p_{3}\right) \\
\partial p_{3} / \partial x_{t}=p_{3}\left(\beta_{3}\left(1-p_{3}\right)-\beta_{2} p_{2}\right)
\end{array}
$$

However, three points can be made about theses parameters. First, if $\beta_{2}$ and $\beta_{3}$ have the same signs, one can say that the effect of $x_{t}$ on the probability of the reference state $\left(p_{1}\right)$ is the opposite to that sign. Second, if $\beta_{2}$ and $\beta_{3}$ have opposite signs, then the effects of the variable on the probability of the non-reference alternatives follow the same direction as the sign of the parameter corresponding to them, i.e., in this case, the effect of $x_{t}$ on $p_{2}$ will have the same sign as $\beta_{2}$. Third, even if one of the coefficients is zero, the variable may still have effects on all the three probabilities.

From the table, we can see that the coefficients of Aboriginal and Torres Islanders are negative and significant for both alternatives. This means Aboriginal are significantly more likely to receive income support payments than others - indicating that they relied more often on welfare system than others, but it is not clear the effect on which of the two latter probabilities is negative. Being born in Australia, on the other hand, significantly reduced the likelihood of relying on income support payments. Not surprisingly, we find that the younger the youngest child was, the more likely that the mother received income support payments a quarter later. Interestingly, due to the insignificance of the 
parameter for FA only and the significance of that for 'out', the more children under 13 and between 15-16 she has, the more likely she receives income support payments or FA only, and less likely to leave the system.

Time spent on the system also plays a role-We find that the longer the person has stayed on the system, the higher the probability that she receives income support payment or FA.

Both having a partner and home-ownership would decrease significantly the likelihood of receiving income support payments the following quarter. The positive significant estimates of the coefficients for the partner dummy corresponding to both FA only and out of system indicate that lone mothers were more likely to be receiving income support payments a quarter later, and hence depended more likely on welfare system. The estimates also show that except for Perth, Canberra and Darwin, mothers in the whole country were more likely to be receiving income support payments than in Sydney. This may indicate a better (part-time) employment opportunities in Sydney.

From the estimates of $\gamma_{j}$ and the estimates of the parameters for the variancecovariance matrix of the random effects, we can see that both state dependence and heterogeneity play roles. The positive significant signs of coefficients of the lagged dependent variable reveal the state dependence and indicate that an individual who receives FA only is more likely to be receiving FA only or leaving the system in the next quarter than a similar individual who received income support payment. The variances and the covariances of the random effects are in the last part of Table 4. The results show that the random effects play a significant role and the two individual heterogeneity terms are positively correlated.

To Show the magnitudes of these effects we calculated the marginal effects for the 'average person' in the second quarter of 1997. The quotation indicates the fact for this person, all the continuous variables are set at the sample mean, but the dummies are set at the value with the largest sample probability. The results are in Table 6 . The left panel is for the case if she were on welfare during the previous quarter, and the right panel is for the case if she received FA only the quarter before. We find that the effects of all variables are stronger when she were on welfare than otherwise. From the table we can see that, among all the variables, being partnered, partner on welfare, being Aboriginal, and born in Australia are the ones having dominant effects. Firstly, being partnered would reduce the likelihood on welfare by 0.25 and 0.21 , respectively, depending on whether she was on welfare or not. On the other hand, partner on welfare will increase the odds for her to be on welfare by 0.23 and 0.14 , respectively. Thirdly, most of other variables also have statistically significant effects. For example, in the first case, if she were an Aboriginal, her chance to be on welfare would be 0.08 more, and at the same time, her chances of receiving FA only and leave the system would be reduced by 0.035 and 0.040 , respectively, ceteris paribus; in the second case, whether she is an Aboriginal does not matter much for these probabilities. Fourthly, being born in Australia would reduce her chance on welfare by 0.07 if she was on welfare the previous 
quarter, and only 0.01 otherwise.

Table 5. Parameter Estimates of the dynamic equation

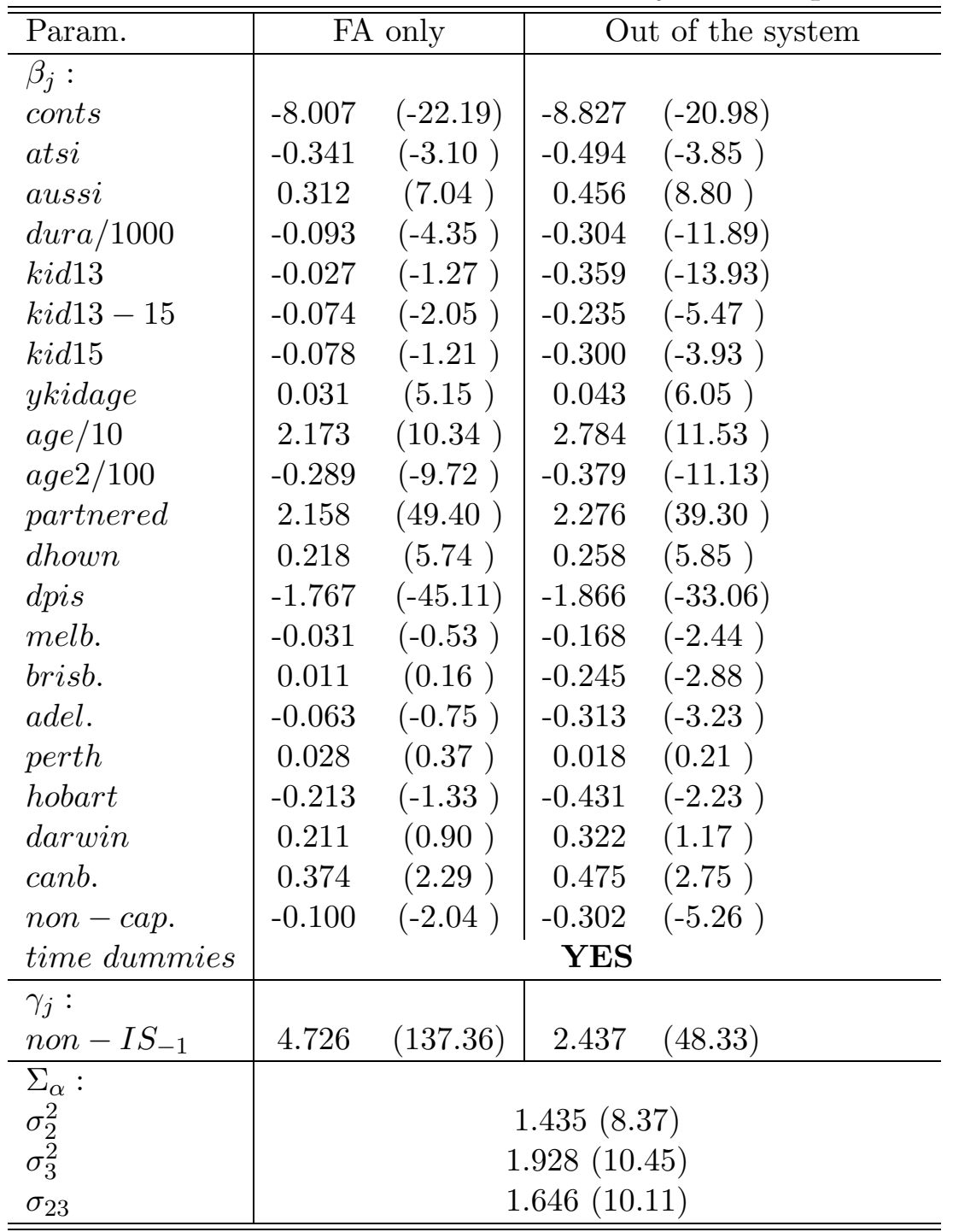

Notes:

'FA only' means more than the minimum rate of FA only.

In the parentheses are $t-$ values.

Reference state: IS payments

$\sigma_{j}^{2}$ : variance of $\alpha_{i j}, j=2,3$;

$\sigma_{23}$ : covariance of $\alpha_{i 2}$ and $\alpha_{i 3}$ 
Table 6. Marginal Effects on the probabilities of the explanatory variables

\begin{tabular}{l|ccc|ccc}
\hline \hline & \multicolumn{3}{|c|}{ Lagged state: IS } & \multicolumn{3}{c}{ Lagged state: FA } \\
Variables & IS & FA & out & IS & FA & out \\
atsi & $0.075(0.019)$ & $-0.035(0.013)$ & $-0.040(0.011)$ & $0.014(0.005)$ & $-0.004(0.009)$ & $-.010(0.007)$ \\
aussi & $-0.071(0.009)$ & $0.032(0.006)$ & $0.038(0.007)$ & $-0.012(0.002)$ & $0.003(0.003)$ & $0.010(0.003)$ \\
dura/1000 & $0.035(0.024)$ & $-0.003(0.023)$ & $-0.031(0.015)$ & $0.004(0.006)$ & $0.009(0.018)$ & $-.013(0.014)$ \\
kid13 & $0.035(0.006)$ & $0.004(0.003)$ & $-0.039(0.005)$ & $0.002(0.001)$ & $0.020(0.004)$ & $-.022(0.004)$ \\
kid13 -15 & $0.030(0.008)$ & $-0.005(0.005)$ & $-0.025(0.005)$ & $0.003(0.001)$ & $0.008(0.003)$ & $-.011(0.003)$ \\
kid15 & $0.036(0.014)$ & $-0.005(0.008)$ & $-0.031(0.009)$ & $0.003(0.002)$ & $0.011(0.006)$ & $-.014(0.005)$ \\
ykidage & $-0.007(0.001)$ & $0.003(0.001)$ & $0.004(0.001)$ & $-0.001(0.000)$ & $0.000(0.000)$ & $0.001(0.000)$ \\
age/10 & $-0.043(0.007)$ & $0.025(0.005)$ & $0.018(0.005)$ & $-0.007(0.001)$ & $0.007(0.003)$ & $0.000(0.002)$ \\
partnered & $-0.250(0.020)$ & $0.141(0.018)$ & $0.109(0.015)$ & $-0.201(0.023)$ & $0.180(0.020)$ & $0.021(0.006)$ \\
dhown & $-0.051(0.008)$ & $0.026(0.006)$ & $0.026(0.006)$ & $-0.007(0.001)$ & $0.003(0.003)$ & $0.003(0.002)$ \\
dpis & $0.230(0.018)$ & $-0.129(0.016)$ & $-0.101(0.014)$ & $0.138(0.017)$ & $-0.123(0.015)$ & $-.015(0.005)$ \\
melb. & $0.018(0.012)$ & $-0.001(0.007)$ & $-0.017(0.007)$ & $0.001(0.002)$ & $0.007(0.004)$ & $-.009(0.004)$ \\
brisb. & $0.018(0.014)$ & $0.006(0.009)$ & $-0.025(0.008)$ & $0.000(0.002)$ & $0.015(0.005)$ & $-.015(0.005)$ \\
adel. & $0.033(0.016)$ & $-0.003(0.010)$ & $-0.030(0.009)$ & $0.003(0.003)$ & $0.012(0.006)$ & $-.015(0.005)$ \\
perth & $-0.005(0.016)$ & $0.004(0.009)$ & $0.001(0.009)$ & $-0.001(0.002)$ & $0.001(0.005)$ & $-.001(0.004)$ \\
hobart & $0.056(0.028)$ & $-0.020(0.019)$ & $-0.036(0.015)$ & $0.009(0.006)$ & $0.004(0.012)$ & $-.013(0.009)$ \\
darwin & $-0.058(0.053)$ & $0.022(0.031)$ & $0.035(0.033)$ & $-0.006(0.007)$ & $-0.003(0.016)$ & $0.009(0.014)$ \\
canb. & $-0.094(0.036)$ & $0.044(0.023)$ & $0.050(0.022)$ & $-0.010(0.004)$ & $0.003(0.011)$ & $0.008(0.009)$ \\
non-cap. & $0.036(0.010)$ & $-0.008(0.006)$ & $-0.028(0.006)$ & $0.004(0.002)$ & $0.008(0.004)$ & $-.012(0.004)$ \\
\hline
\end{tabular}

For the mean person in the second quarter of 1997.

Standard errors are in the parentheses.

\section{Simulations}

In this section, we present some simulated transition probabilities for some benchmark person to look more closely the mobility patterns and also to illustrate the effects of various variables on them. The simulations are conducted for the first two quarters, with individual characteristics and the unobserved heterogeneity terms (random effects) fixed at certain values. The results are summarized in Table 7. Standard errors of the probabilities are estimated by repeating the simulations for a large number of draws (1000 draws in our case) from the estimated asymptotic distribution of the parameter estimates. As a sensitivity test, a simulation which based upon the variances of the random effects set to 1.5 times of their point estimates was also conducted. The results are very similar to those in Table 7 and hence were not reported.

In the first panel of the table, the probabilities of all the states in the first and the second quarter are calculated for a person with bench mark observed characteristics (who were 33 years old, have spent 800 days (about 57 fortnights) on the system, partnered with one six-year-old child only, not a home owner, and partner not on income support 
payments). Her unobserved heterogeneity is set at the mean, 0. It is apparent that different lagged status she was in leads to very different transition probabilities.

The first column in Table 7 gives the probabilities of the individual in the initial quarter. For example, for the benchmark person, the probability of receiving income support payments was about $34.5 \%$ in the first quarter, while that of receiving FA only was $65.5 \%$. The upper left part of each panel gives the conditional probabilities in the second quarter. For example, if the bench mark person received income support payments, her chance of remaining on income support payments was $70.3 \%$, and the chance of moving to FA only was $14.7 \%$. If she received FA only in the first quarter, however, the chance of remaining there is $87.3 \%$. For this person, FA only is a more 'stable' state, i.e., she is more likely to remain there than she remains in IS, and she is more likely to move from IS to FA only than the other way around. Her probability of leaving the system is about $15 \%$ if she was in IS and $9 \%$ if she was in FA only, but relatively speaking, among the leavers, the ones who leave FA only is more likely to leave the system than the ones who leave IS (0.09:0.037 vs 0.150:0.147).

In the other panels of the table, the same information are provided for persons who only differ from the bench mark person in one aspect only. For example, the second panel of Table 7 refers to persons who was the same as the benchmark person except that they had spent another 800 days longer.

In the final row in each panel, the probabilities in the second quarter are presented. Again, for the bench mark person, the probability of receiving income support payments and non-income support payments were $26.7 \%$ and $62.2 \%$, respectively. ${ }^{5}$

From the table we can find that, being on the system a bit longer, different housing condition, being a bit older, and so on all affect the transition matrix, but only marginally. For example, the person who stayed 800 days longer than the bench mark person has less chance to be out of the system, but the difference with the bench mark person is only significant when she is in IS. On the other hand, once her partner is on income support or she becomes a single mother, not only the probabilities in the two states are changed dramatically (the probabilities on IS are more than $90 \%$ compared to $34.5 \%$ for the bench mark person), but also the dynamics. For these persons, IS is the more 'stable' state - the likelihood of remaining there are $94 \%$ and $96 \%$, for the two persons, respectively, implying they are more likely to be trapped in that state. Their chances of moving to FA only and out of the system are equally dramatically reduced. Even if they were lucky to be in FA only, there chances to dropped back into IS are also increased drastically $-18.5 \%$ for the one with a IS partner and $25.1 \%$ for the single mother - compared to $4 \%$ for the benchmark person. However, being in FA only does now lead to a significantly better chance to leave the system than being in the state of IS, for example, for a person whose partner is on IS as well, her chance of leaving the

\footnotetext{
${ }^{5}$ They cannot be compared with the numbers in the first quarter directly, which are the conditional probabilities given the individuals remained in the system. Their counterparts in the second quarter can be recovered easily. For example, in this case, the conditional probabilities in the second quarter are $30.0 \%$ and $70.0 \%$, respectively.
} 
system is $7.0 \%$ when she received FA only, and is only $3.1 \%$ if she was on IS.

To show the effect of the random effects, in the last panel of Table 7 , the values of the random effects are set to one standard deviation away from the mean, 0. Comparing with the first panel, we can see that the effects on both the static likelihood and the transition matrix are very strong.

Table 7. Simulated Transition Probabilities

\begin{tabular}{|c|c|c|c|c|}
\hline \multirow[b]{2}{*}{$j_{t}$} & \multirow{2}{*}{$\frac{\operatorname{Prob}\left(j_{t} \mid i_{t}<3\right)}{t=1}$} & \multicolumn{3}{|c|}{\begin{tabular}{l|l}
$\operatorname{Prob}\left(J_{2}\right.$ & $\left.j_{1}\right)$ \\
\end{tabular}} \\
\hline & & IS payments & FA only & Out \\
\hline \multicolumn{5}{|l|}{ Bench mark person } \\
\hline \multirow[t]{2}{*}{ IS payments } & 0.345 & 0.703 & 0.147 & 0.150 \\
\hline & $(0.02)$ & $(0.02)$ & $(0.01)$ & $(0.01)$ \\
\hline \multirow[t]{2}{*}{ FA only } & 0.655 & 0.037 & 0.873 & 0.090 \\
\hline & $(0.02)$ & $(0.003)$ & $(0.01)$ & $(0.01)$ \\
\hline \multirow[t]{2}{*}{$\operatorname{Prob}\left(j_{t}\right)$} & $t=2$ & 0.267 & 0.622 & 0.111 \\
\hline & & $(0.02)$ & $(0.02)$ & $(0.01)$ \\
\hline \multicolumn{5}{|l|}{800 days longer on LDS } \\
\hline \multirow[t]{2}{*}{ IS payments } & 0.374 & 0.734 & 0.143 & 0.123 \\
\hline & $(0.03)$ & $(0.02)$ & $(0.01)$ & $(0.01)$ \\
\hline \multirow[t]{2}{*}{ FA only } & 0.626 & 0.040 & 0.882 & 0.078 \\
\hline & $(0.03)$ & $(0.004)$ & $(0.01)$ & $(0.01)$ \\
\hline \multirow[t]{2}{*}{$\operatorname{Prob}\left(j_{t}\right)$} & $t=2$ & 0.300 & 0.606 & 0.095 \\
\hline & & $(0.02)$ & $(0.03)$ & $(0.01)$ \\
\hline \multicolumn{5}{|l|}{ Home-owner } \\
\hline \multirow[t]{2}{*}{ IS payments } & 0.323 & 0.651 & 0.170 & 0.180 \\
\hline & $(0.02)$ & $(0.02)$ & $(0.01)$ & $(0.01)$ \\
\hline \multirow[t]{2}{*}{ FA only } & 0.677 & 0.030 & 0.876 & 0.095 \\
\hline & $(0.02)$ & $(0.002)$ & $(0.01)$ & $(0.01)$ \\
\hline \multirow[t]{2}{*}{$\operatorname{Prob}\left(j_{t}\right)$} & $t=2$ & 0.231 & 0.647 & 0.122 \\
\hline & & $(0.02)$ & $(0.02)$ & $(0.01)$ \\
\hline \multicolumn{5}{|l|}{ Partner on IS programs } \\
\hline \multirow[t]{2}{*}{ IS payments } & 0.909 & 0.935 & 0.034 & 0.031 \\
\hline & $(0.01)$ & $(0.01)$ & $(0.003)$ & $(0.003)$ \\
\hline \multirow[t]{2}{*}{ FA only } & 0.091 & 0.185 & 0.745 & 0.070 \\
\hline & $(0.01)$ & $(0.01)$ & $(0.02)$ & $(0.01)$ \\
\hline \multirow[t]{2}{*}{$\operatorname{Prob}\left(j_{t}\right)$} & $t=2$ & 0.867 & 0.099 & 0.035 \\
\hline & & $(0.01)$ & $(0.01)$ & $(0.003)$ \\
\hline
\end{tabular}

'FA only' means more than the minimum rate of FA only.

Standard errors are in parentheses. 
Table 7. Simulated Transition Probabilities(continued)

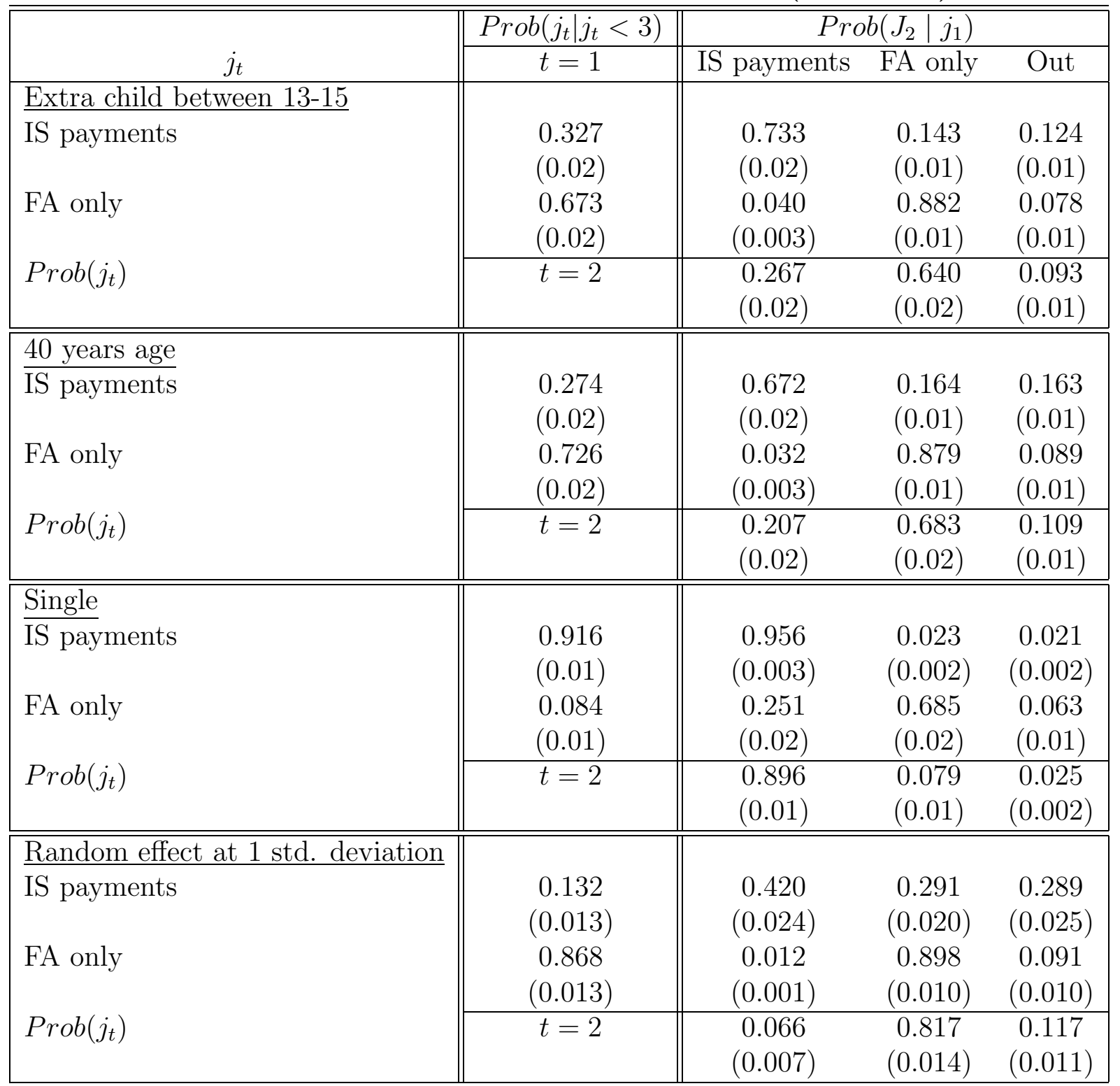

'FA only' means more than the minimum rate of FA only.

Standard errors are in parentheses.

\section{Conclusions}

We have investigated the welfare dependency of females with dependent children in Australia by studying the mobility patterns among the three states, receiving income 
support payments, receiving more than the minimum rate of FA only, and an absorbing state where the individuals were off the system. Including the absorbing state, we believe, takes account the potential sample selection problem. A random effects dynamic multinomial logit model was estimated using simulated maximum likelihood methods for LDS data set covering 14 quarters.

We find both 'true' state dependence and unobserved heterogeneity play significant roles in the process. 'True' state dependence indicates the existence of 'welfare trap': once the individual relies on the welfare system, it is rather hard for them to escape from it. Meanwhile, the significance of the coefficients for those observed characteristics and the random effect indicates that certain type of individuals are more likely to be relying on welfare than others. The effects are illustrated by the marginal effects and the simulated probabilities of individuals with different values of random effects. In particular, the probability of receiving income support payments strongly increases if the individual was single - the marginal effect of being partnered on the probability for the average person is 25 percentage points if she was on IS; the dependence on welfare system of the partner also influences that of the individual: the probability for the individual receiving income support payments is higher if her partner received income support payment - for the average person, the probability of being on welfare would be 23 percentage points more if her partner was also on IS, given she was on IS in the previous quarter. Since many potentially important variables, for example, education, family background, and so on, are not observed in the data set, it is possible that their effects are picked up by the random effects. Age, location of residence, age of children are all factors significantly influencing welfare dependency, but the magnitude of the effects on the transition matrix are not very large.

The simulated probabilities of transitions for a benchmark individual in different states and for different individuals in the same period were compared. The results illustrate the effects on the transition matrix. They also show that the random effects, or unobserved heterogeneity, play important roles together with the lagged state.

Hence, the increases of welfare dependency over time are the results of increases of certain group of people on the welfare system, for example, single mothers with young children, who are more likely to dependent on welfare system and less likely to escape from it, and are the results of state dependence, i.e., once a person is on the system, she is more likely to stay there.

Some limitation of our approach and directions for future research seem worth mentioning. The first is that, as mentioned above, many important variables are missing from the data set. For the study to be of more value to policy makers, the effects of these variables need to be modelled and analyzed more explicitly. Secondly, information is missing once individuals leave the system, so it is not possible to analyze the transition into the income support system. For example, it is not possible to answer who are more likely to rely on welfare, and so on. Thirdly, the study is a descriptive one. For evaluating the income policy change, for example, one need to know the individuals 
labor supply behavior. Hence, a natural extension of the study is to model individuals' decision on employment and/or family formation for a given welfare system and the response to a change of it.

However, to to overcome these limitation, more information is needed, for example, from survey data. 


\section{References}

Barrett, G. (2000), "The dynamics of participation in Parenting Payment (Single) and the Sole Parent Pension," Policy Research Paper No 14, FaCs, Australia.

Card, D and D. Hyslop (2002), "Estimating the dynamic treatment effects of an earnings subsidy for welfare leavers,", UC Berkeley, Center for Labor Economics, Working paper, 47.

FaCs. 2000, Department of Family and Community Services Income Support Customers - A statistical overview.

Gregory, R. and E. Klug, 2003, "A Picture Book Primer: Welfare Dependency and the Dynamics of Female Lone Parent Spells," manuscript, Australian National University.

Heckman, J. (1981a), "Statistical Models for Discrete Panel Data," in Structural Analysis of Discrete Data with Econometric Applications, ed by Manski, C. and D. McFadden, the MIT Press, London, 114-179.

Heckman, J. (1981b), "The incidental Parameters Problem and the Problem of Initial Conditions in Estimating a Discrete Time-Discrete Data Stochastic Process," in Structural Analysis of Discrete Data with Econometric Applications, ed by Manski, C. and D. McFadden, the MIT Press, London, 114-179.

Heckman, J. and G. Sedlacek (1985), "Heterogeneity, aggregation and market wage functions: an empirical model of self-selection in the labor market," Journal of Political Economy 93, 1077-1125.

Kumar, A. and J. De Maio (2002), "Welfare Dynamics of Mature Age Customers: An Analysis using the FaCs Longitudinal Data Set," mimeo, Australia Bureau of Statistics, Australia.

Lee, L.-F. (1992), "On efficiency of methods of simulated moments and maximum simulated likelihood estimation of discrete response models," Econometric Theory 8, 518-552.

Whiteford, P. (2000), "The Australian System of Social Protection-an Overview, Policy Research Paper No1, FaCs, Australia."

Wooldridge, J. (2002), "Simple Solutions to the Initial Conditions Problem in Dynamic, Nonlinear Panel Data Models with Unobserved Heterogeneity," Institute of Fiscal Studies, Department of Economics, UCL, working paper CWP 18/02. 


\section{Appendix:}

Table A1. Variables used in the analysis

\begin{tabular}{r|l}
\hline \hline Variables & Explanations \\
\hline atsi & Aboriginal and Torres Islanders \\
inc & Born in Australia \\
dura & Fortnightly income (current dollars) \\
kids $s_{u} 13$ & No. of Children under 13 \\
kids 1315 & No. of Children between 13 and 15 \\
kids 15 & No. of Children over 15 \\
ykidage & age of the youngest child \\
age & age \\
dis & dummy on an income support payment \\
partnered & partnered \\
dhown & home owner \\
dpis & partner on an income support payment \\
dpnis & partner on non-income support payments \\
sydney & lives in Sydney \\
melbourne & lives in Melbourne \\
brisbane & lives in Brisbane \\
adelaide & lives in Adelaide \\
perth & lives in Perth \\
hobart & lives in Hobart \\
darwin & lives in Darwin \\
canberra & lives in Canberra \\
Obs. & No. of Observations \\
\hline
\end{tabular}


Table A2. Parameter Estimates of the initial equation

\begin{tabular}{l|cc}
\hline \hline Param. & Non-IS payments & \\
\hline$\beta_{j}:$ & & \\
conts & -8.607 & $(-17.03)$ \\
atsi & -0.116 & $(-0.75)$ \\
aussi & 0.288 & $(4.47)$ \\
dura $/ 1000$ & -0.158 & $(-4.62)$ \\
kid13 & 0.186 & $(5.92)$ \\
kid13-15 & 0.078 & $(1.32)$ \\
kid15 & 0.052 & $(0.43)$ \\
ykidage & 0.047 & $(5.15)$ \\
age/10 & 3.038 & $(10.18)$ \\
age $/ 100$ & -0.386 & $(-8.94)$ \\
partnered & 3.034 & $(39.59)$ \\
dhown & 0.097 & $(1.71)$ \\
dpis & -2.945 & $(-38.33)$ \\
melb. & -0.164 & $(-1.90)$ \\
brisb. & 0.112 & $(1.08)$ \\
adel. & -0.206 & $(-1.66)$ \\
perth. & -0.120 & $(-1.06)$ \\
hobart & -0.749 & $(-2.83)$ \\
darwin & 0.123 & $(0.39)$ \\
canb. & 0.319 & $(1.51)$ \\
non-cap. & -0.164 & $(-2.23)$ \\
$\sigma_{\theta_{2}}^{2}$ & 1.548 & $(11.57)$ \\
timedummies & & \\
Notes: & &
\end{tabular}

Notes:

In the parentheses are $t$ - values.

Reference state: IS payments 
Figure 1. Income Support and Family Allowance in 2000 (Single mother with one child aged under 13 years)

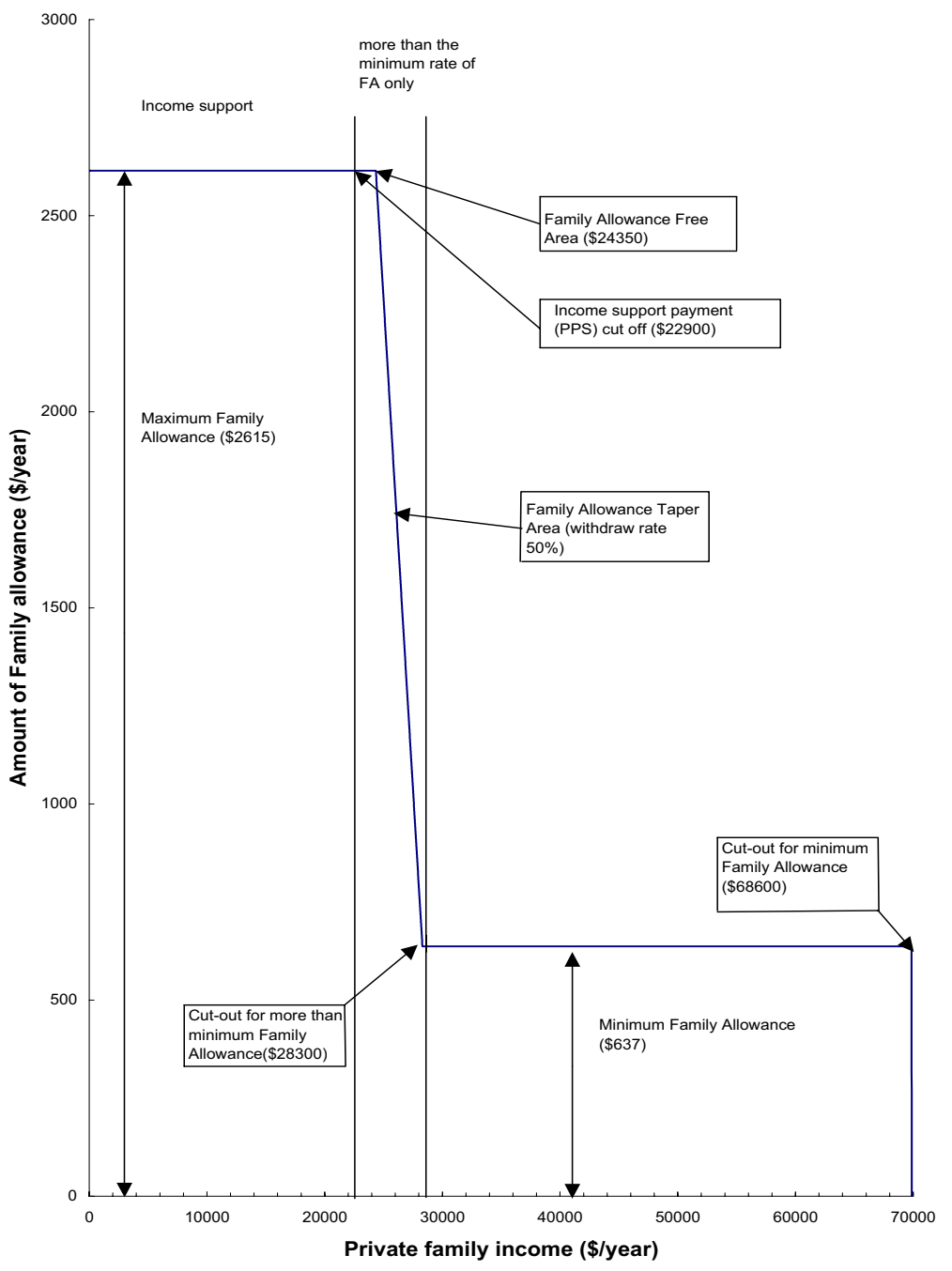


Figure 2. Number of the customers over time

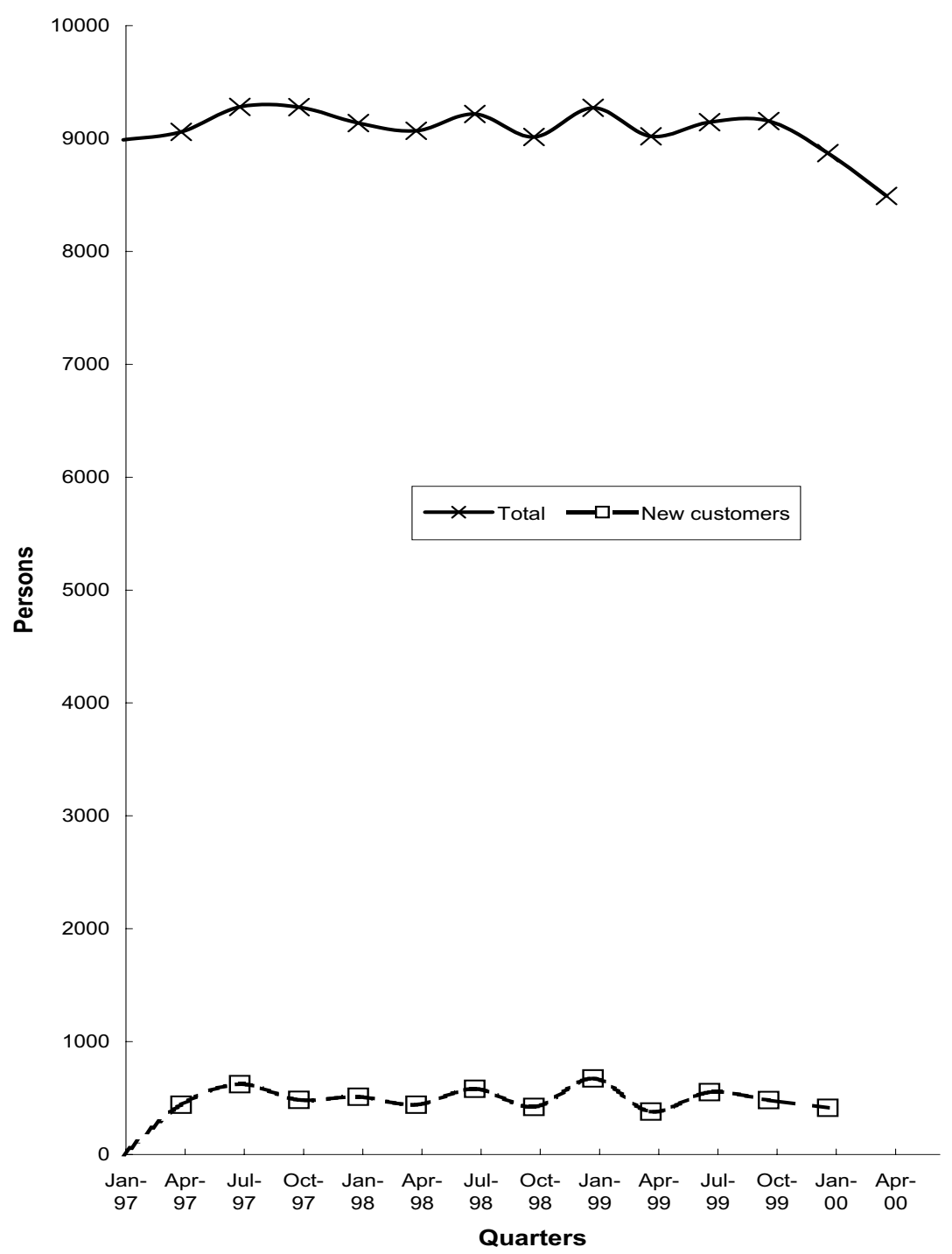


Figure 3. Composition of the females with children over time

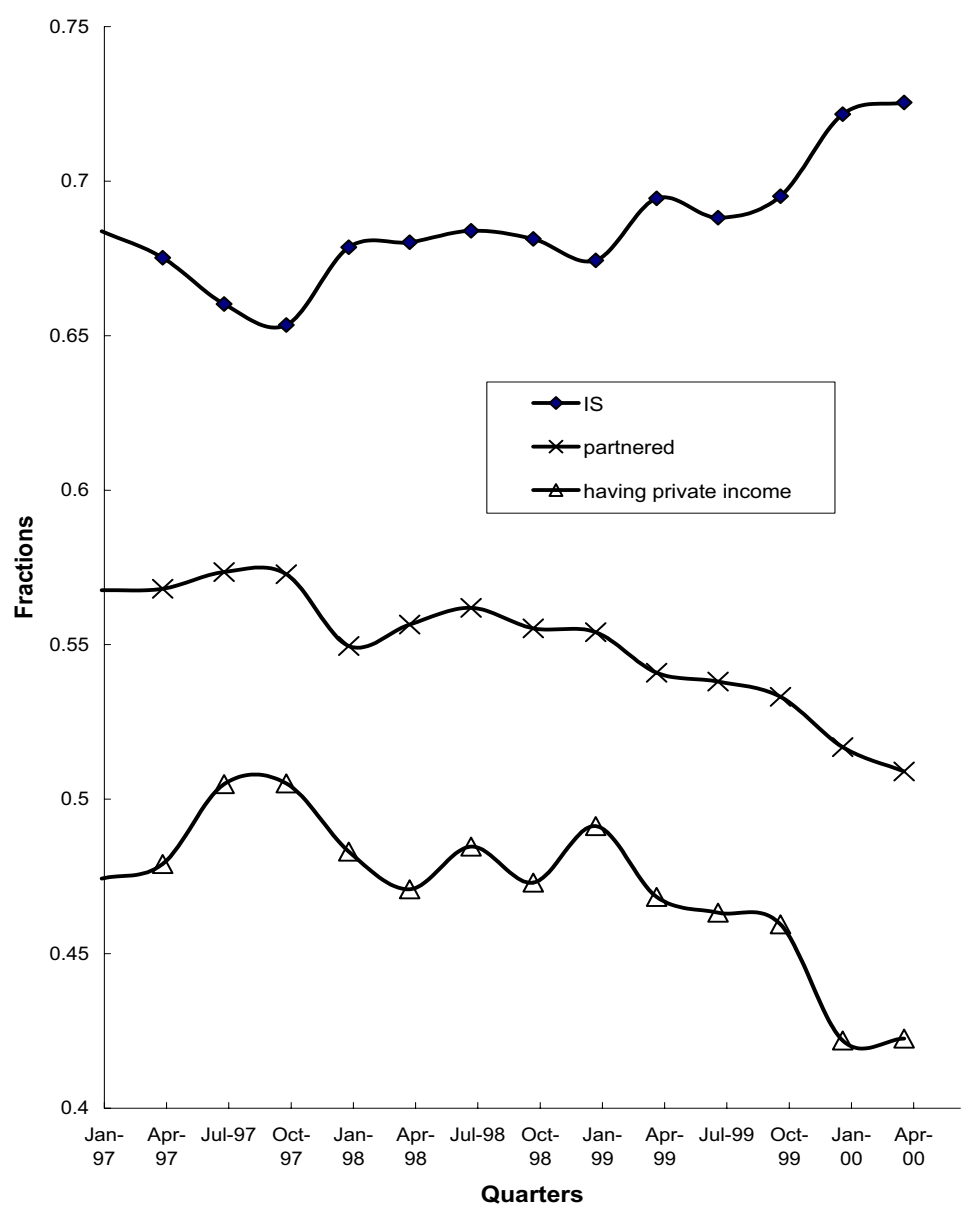

